Aryuni

Rusdianti $^{1}$

Yeni Solfiah $^{2}$

Rita Kurnia ${ }^{3}$

\section{PENGEMBANGAN MEDIA GETAR ( GEOMETRI PUTAR) UNTUK MENINGKATKAN KEMAMPUAN MENGENAL BENTUK GEOMETRI PADA ANAK USIA 4-5 TAHUN}

\begin{abstract}
Abstrak
Penelitian ini bertujuan untuk menghasilkan produk berupa Media Getar (Geometri Putar) untuk meningkatkan kemampuan mengenal bentuk geometri pada anak usia 4-5 tahun. Jenis penelitian ini menggunakan metode Research and Development Brog \& Gall. Prosedur pengembangan terdiri dari beberapa tahap yakni potensi dan masalah, mengumpulkan informasi, desain produk, validasi poduk, dan revisi produk. Dalam penelitian ini tidak ada uji coba media ke TK dikarenakan pandemi Covid-19. Dari analisis data dapat dilihat bahwa hasil penilaian dari validator ahli materi memperoleh persentase sebesar $90 \%$ dengan kategori sangat layak. Penilaian dari validator ahli media memperoleh persentase sebesar $84,7 \%$ dengan kategori sangat layak dengan saran untuk menggubah warna biru pada media dan ukuran tulisan lebih dibesarkan. Selanjutnya penilaian oleh 5 guru TK yang sertifikasi mendapatkan persentase sebesar 86,62\% dengan kategori sangat layak. Sehingga dapat disimpulkan bahwa Media Getar (Geometri Putar) layak digunakan dalam kegiatan pembelajaran pengenalan bentuk geometri pada anak usia 4-5 tahun.
\end{abstract}

Kata Kunci: Mengenal Bentuk Geometri, Media Getar (Geometri Putar)

\begin{abstract}
The purpose of this research is to produce a product which is vibrating media (rotary geometry) to improve ability in recognize geometric shapes in children aged 4-5 years. The design of this research is research and development $(\mathrm{R} \& \mathrm{D})$ Brog \& Gall method. The development producing consists of several stages, namely potentials and problems, gathering information, product design, product validation, and product revision. In this research, there was no media test to kindergarten due to the covid-19 pandemic. Based on the data analysis, it can be seen that the result of the assesment by the material expert validator get a percentage of $90 \%$ with very feasible category. Baside that the assesment of the media expert validator obtained a percentage of $84,7 \%$ with suggestions to change the blue color on the media and to increase the size of writing. Furthermore, the assesment by 5 certified kindergarten teachers get a percentage of $86,62 \%$ with a very feasible category. Thus, it can be conculded that the vibrating media (rotary geometry) is suitable to use in learning the introduction of geometric shapes in children aged 45 years.
\end{abstract}

Keywords: Recognize Geometric Shapes, Vibrating Media (Rotary Geometry)

1,2,3) Program Studi Pendidikan Guru Pendidikan Anak Usia Dini, Fakultas Keguruan dan Ilmu Pendidikan, Universitas Riau

${ }^{1)}$ Alamat email aryunirusdianti9@gmail.com

${ }^{2)}$ Alamat email yeni.solfiah@lecturer.unri.ac.id

${ }^{3)}$ Alamat email rita.kurnia@lecturer.unri.ac.id 


\section{PENDAHULUAN}

Anak adalah manusia kecil yang memiliki potensi-potensi yang harus dikembangkan, anak merupakan penerus bangsa, sehingga kehadirannya begitu dinantikan oleh setiap manusia, baik itu dalam lingkungan keluarga maupun lingkungan masyarakat. Masa usia prasekolah disebut juga masa keemasan bagi anak (golden age) dimana perkembangan otak pada anak sangat berkembang pesat yaitu sekitar 50\% pada usia 0-6 tahun, sehingga dapat menerima berbagai rangsangan atau stimulus dari lingkungan sekitar anak baik yang berkaitan dengan aspek moral agama, sosial emosional, bahasa, kognitif, dan motorik. Potensi-potensi tersebut distimulus dan dikembangkan agar anak dapat berkembang secara optimal. Perkembangan dan pertumbuhan pada anak harus distimulasi dengan baik, agar tugas perkembangannya dapat berkembang secara optimal (Agung Triharso, 2013). Dalam pertumbuhannya anak-anak tidak dapat dipisahkan dari benda-benda yang ada disekitarnya. Sejak kecil anak sudah mengenal bendabenda terdekatnya yang bentuknya sama dengan bentuk geometri, misalnya koin, lemari, meja, buku, bola, atau benda lain yang digunakan untuk memenuhi kebutuhan dalam kehidupan sehari-hari dan keperluan bermain (Latif,dkk,2013).

Agung Triharsono (2013) menyatakan bahwa dalam membangun konsep geometri pada anak dimulai dari mengindentifikasi bentuk-bentuk, menyelidiki bengunan dan memisahkan gambar-gambar biasa seperti segi empat, lingkaran, dan segitiga. Kemampuan pengembangan konsep geometri berhubungan dengan pengembangan konsep bentuk dan ukuran. Menurut Wahyudi CHA dan Dwi Retno Damayanti (2005) Kemampuan geometri yang harus dikembangkan pada anak usia dini antara lain: (1) Pengenalan bentuk dasar: lingkaran, pesegi dan segitiga (2) Membedakan bentuk-bentuk geometri (3) Memberi nama, menghubungkan bentuk dengan namanya (4) Menggolongkan bentuk dalam suatu kelompok sesuai dengan bentuknya (5) Mengenali bentuk-bentuk benda yang ada dilingkungannya sendiri.

Kemampuan mengenal bentuk geometri pada anak usia dini dapat disimulasi dengan berbagai media yang sesuai dengan karakteristik dan aspek perkembangan anak usia dini. Media berperan penting dalam proses belajar mengajar yang dapat membantu guru untuk menyampaikan sebuah informasi melalui media tersebut. Menurut Azhar Arsyad (2013) media adalah semua bentuk perantara yang digunakan oleh manusia untuk menyampaikan atau menyebar ide, gagasan, atau pendapat, seingga ide, gagasan, dan pendapat yang dikemukakan itu sampai kepada penerima yang dituju

Berdasarkan hasil observasi, peneliti mendapatkan beberapa masalah berkaitan dengan pembelajaran geometri pada anak. Hal ini disebabkan karena penyajian ketika pembelajaran geometri yang disampaikan guru tidak menarik yaitu tanpa menunjukkan dan menggunakan media yang dapat dilihat langsung oleh anak, guru juga hanya bercerita dan menerangkan gambar betuk geometri yang digambarkan di papan tulis, terkadang guru menggunakan LKA dalam pembelajaran geometri, pembelajaran pun tanpa diselingi dengan kegiatan bermain menggunakan alat permainan. Sehingga anak-anak masih kebingunggan saat ditanya dan diminta untuk menyebutkan macam-macam bentuk-bentuk geometri seperti bentuk segi empat, segitiga, dan lingkaran.

Berdasarkan uraian tersebut peneliti ingin melakukan penelitian dan pengembangan sebuah produk yaitu Media Getar (geometri putar). Media Getar (geometri putar) adalah sebuah media yang terinspirasi dari permainan gotri legendri, media ini di desain secara unik dan kreatif untuk memenuhi kebutuhan dari proses pembelajaran yang akan dikenalkan kepada anak. Seperti mengenalkan bentuk-bentuk geometri (lingkaran, segi empat, segi tiga), dimana anak akan melakukan kegiatan dengan tahapan-tahapan mengenal bentuk geometri yang sesuai dengan kemampuan anak usia 4-5 tahun, berupa sebuah lingkaran berputar, yang terdapat macammacam bentuk geometri (segi empat, segitiga dan ligkaran) di dalamnya. Berdasarkan uraian di atas, maka peneliti melakukan penelitian dan pengembangan dengan judul "Pengembangan Media Getar (geometri putar) Untuk Meningkatkan Kemampuan Mengenal Bentuk Geometri Pada Anak Usia 4-5 Tahun" 


\section{METODE}

Metode yang digunakan dalam penelitian ini adalah Research and Development dari Brog \& Gall (dalam Sugiyono, 2013). Yang terdiri dari 7 tahapan tetapi dalam penelitian ini disederhanakan menjadi 5 tahapan dikarenakan pandemi Covid-19. Penelitian dilaksanakan hanya sampai tahap revisi produk berdasarkan saran dari validator. Validator dalam penelitian ini terdiri dari ahli media, ahli materi, dan 5 guru TK sertifikasi untuk menilai kelayakan produk yang dikembangkan.

Instrument pengumpulan data yang digunakan dalam penelitian pengembangan ini adalah angket untuk ahli materi, angket untuk ahli media dan pendidik. Sedangkan teknik analisis data yang digunakan adalah dengan rumus

$$
\frac{\overline{\mathrm{X}}=\sum_{\mathrm{i}}^{\mathrm{n}} \overline{\mathrm{x}} \mathrm{i}}{\mathrm{n}}
$$

Keterangan:

Dengan:

$$
\begin{aligned}
& \overline{\mathrm{X}}=\text { rata }- \text { rata penilaian dari para validator } \\
& \overline{\mathrm{x}} \mathrm{i}=\text { rata }- \text { rata skor hasil penilaian validator } \mathrm{ke}-\mathrm{i} \\
& \mathrm{n}=\text { banyaknya validator }
\end{aligned}
$$

$$
\overline{\mathrm{x}} \mathrm{i}=\frac{\text { Jumlah Skor }}{\text { Skor maksimal }} \times 100
$$

Skala pengukuran penelitian pengembangan yang telah dimodifikasi dari Riduwan (2012). Untuk keperluan analisis kuantitatif, maka jawaban itu dapat diberi skor tabel berikut:

Tabel 3.4 Skala Likert

\begin{tabular}{ccc}
\hline No & Analisis Kuantitatif & Skor \\
\hline 1 & Sangat Menarik & 5 \\
2 & Menarik & 4 \\
3 & Cukup Menarik & 3 \\
4 & Tidak Menarik & 2 \\
5 & Sangat Tidak Menarik & 1 \\
\hline
\end{tabular}

Sumber: Riduwan (2012)

Hasil dari skor penilaian tersebut kemudian dicari rata-ratanya dari sejumlah subjek sampel uji coba dan dikonversikan kepernyataan penilaian untuk menentukan kualitas dan tingkat kemanfaatan produk yang dihasilkan berdasarkan pendapat pengguna.

\section{Tabel 3.5 Kriteria Kelayakan}

\begin{tabular}{cc}
\hline Skor persentase (\%) & Interpretasi \\
\hline $\mathrm{p}>80 \%$ & Sangat layak \\
$61 \%<\mathrm{P} \leq 80 \%$ & Layak \\
$41 \%<\mathrm{P} \leq 60 \%$ & Cukup layak \\
$20 \%<\mathrm{P} \leq 40 \%$ & Kurang layak \\
$\mathrm{P} \leq 20 \%$ & Sangat kurang layak \\
\hline
\end{tabular}

Sumber: Ridwan (2012)

\section{HASIL DAN PEMBAHASAN}

Pembuatan produk Media Getar (Geometri Putar) sebagai media pembelajaran untuk meningkatkan kemampuan mengenal bentuk geometri pada anak usia 4-5 tahun. Produk divalidasi oleh beberapa ahli yaitu ahli meteri dan ahli media. Kemudian produk juga di validasi oleh lima orang guru taman kanak-kanak yang telah sertivikasi. Ahli juga memberikan saran dan komentar untuk dijadikan acuan dalam memperbaiki produk agar lebih baik dan layak digunakan. Adapun validasi produk oleh ahli sebagai berikut: 
Tabel 1. Hasil Penilaian Validasi Ahli Materi

\begin{tabular}{|c|c|c|c|c|}
\hline $\begin{array}{l}\text { Indikator } \\
\text { penilaian }\end{array}$ & Materi & Skor & $\begin{array}{l}\text { Rata-rata } \\
\text { skor }\end{array}$ & Persentase \\
\hline \multirow{9}{*}{ Materi } & 1. Kesesuian KI dengan KD & 5 & & \\
\hline & $\begin{array}{l}\text { 2. Kesesuaian KD dengan } \\
\text { indikator }\end{array}$ & 4 & & \\
\hline & $\begin{array}{l}\text { 3. Kesesuaian Indikator dengan } \\
\text { materi pembelajaran }\end{array}$ & 5 & & \\
\hline & $\begin{array}{l}\text { 4. Kesesuaian materi dengan } \\
\text { kegiatan pembelajaran } \\
\text { mengenal bentuk geometri }\end{array}$ & 4 & & \\
\hline & 5. Kesesuaian materi dengan & 4 & & \\
\hline & $\begin{array}{l}\text { Media Getar (geometri } \\
\text { putar) }\end{array}$ & & 4,6 & $92 \%$ \\
\hline & $\begin{array}{l}\text { 6. Kesesuian materi dengan } \\
\text { tingkat kemampuan anak } \\
\text { kelompok A }\end{array}$ & 5 & & \\
\hline & 7. Kejelasan isi materi & 5 & & \\
\hline & $\begin{array}{llr}\text { 8. } \begin{array}{l}\text { Kejelasan bahasa } \\
\text { digunakan }\end{array} & \begin{array}{l}\text { yang } \\
\text { dalam }\end{array} \\
\text { penyampaian materi } & \end{array}$ & 5 & & \\
\hline \multirow{9}{*}{$\begin{array}{l}\text { Pengguna } \\
\text { an }\end{array}$} & 9. Kemenarikan isi materi & 5 & & \\
\hline & $\begin{array}{l}\text { 10. Dapat mendorong aktivitas } \\
\text { dan kreativitas anak }\end{array}$ & 4 & & \\
\hline & $\begin{array}{l}\text { 11. Kemudahan pemahaman } \\
\text { materi }\end{array}$ & 4 & & \\
\hline & $\begin{array}{l}\text { 12. Kesesuaian gambar dengan } \\
\text { materi }\end{array}$ & 5 & 4,4 & $88 \%$ \\
\hline & $\begin{array}{l}\text { 13. Kesesuaian bentuk dengan } \\
\text { materi }\end{array}$ & 5 & & \\
\hline & 14. Kemenarikan musik & 4 & & \\
\hline & Total & 64 & 9 & 180 \\
\hline & Rerata skor & 4,5 & 4,5 & $90 \%$ \\
\hline & Kesimpulan & \multicolumn{3}{|c|}{ Sangat layak } \\
\hline
\end{tabular}

Berdasarkan tabel penilaian oleh ahli materi diatas diketahui pada aspek 1 tentang materi mendapat presentase kelayakan $92 \%$, pada aspek 2 tentang penggunaan mendapat persentase kelayakan 88\%. Jumlah skor penilaian 64 dari 14 indikator penilaian. Rata-rata penilaian validator ahli materi yaitu 4,5 dengan presentase kelayakan sebesar $90 \%$.

Tabel 2. Hasil Penilaian Validasi Ahli Media

\begin{tabular}{cclccc}
\hline $\begin{array}{c}\text { Indikator } \\
\text { Penilaian }\end{array}$ & \multicolumn{1}{c}{ Materi } & Skor & $\begin{array}{l}\text { Rata-rata } \\
\text { peraspek }\end{array}$ & Persentase \\
\hline & 1. $\begin{array}{l}\text { Kemenarikan desain } \\
\text { Media Getar (geometri } \\
\text { putar) }\end{array}$ & 4 & & \\
Fisik & 2. $\begin{array}{l}\text { Kesesuaian ukuran Media } \\
\text { Getar (geometri putar) }\end{array}$ & 5 & & \\
& 3. $\begin{array}{l}\text { Kesesuian ukuran bentuk- } \\
\text { bentuk geometri }\end{array}$ & 5 & 4,4 & $88 \%$ \\
& 4. $\begin{array}{l}\text { Keawetan bahan (kuat } \\
\text { dan tahan lama) media }\end{array}$ & 4 & \\
\hline
\end{tabular}




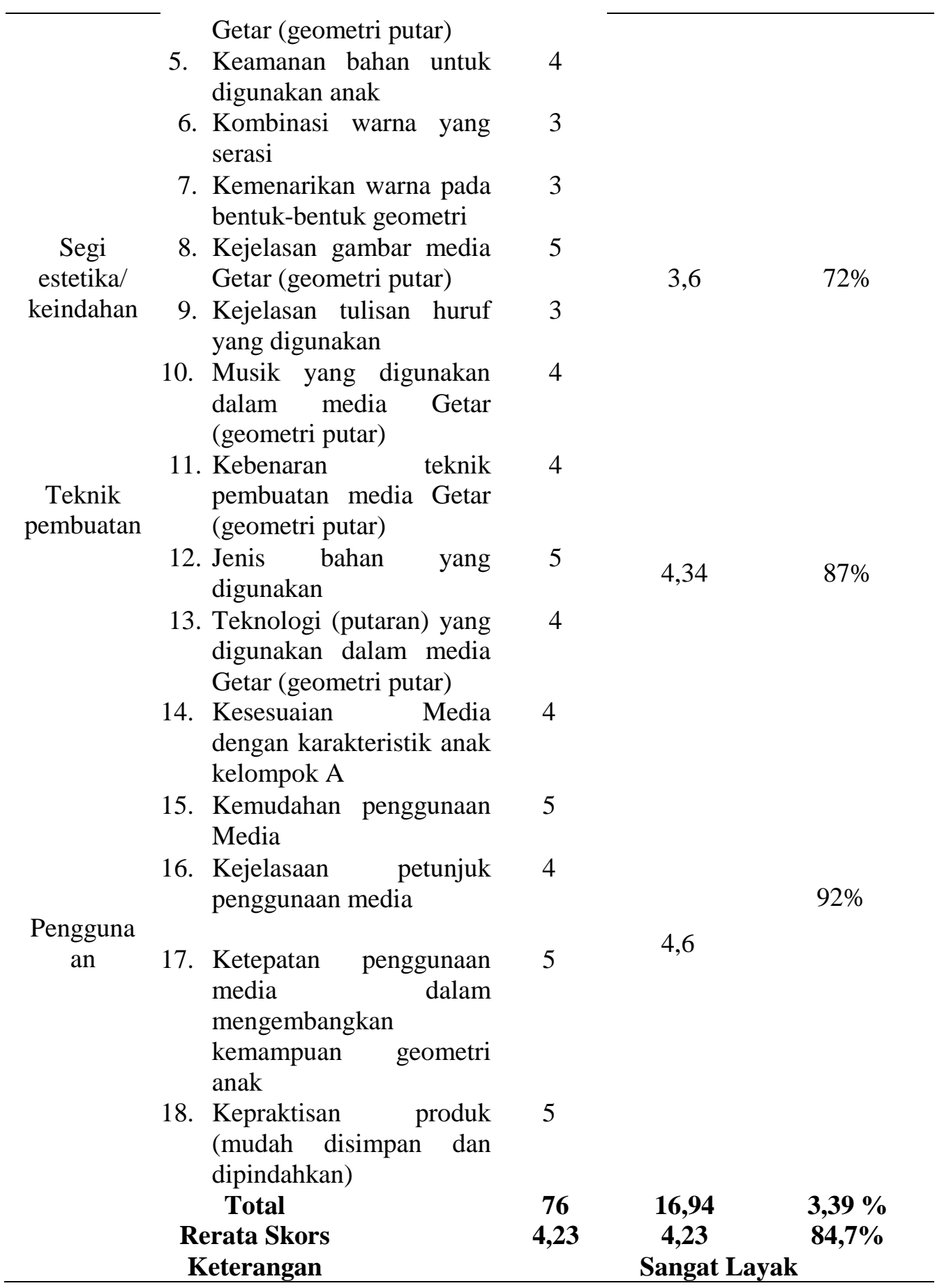

Berdasarkan tabel penilaian oleh ahli media diatas diketahui pada aspek 1 tentang fisik mendapat presentase kelayakan $88 \%$, pada aspek 2 tentang segi estetika/keindahan mendapat presentase kelayakan $72 \%$, pada aspek 3 tentang teknik pembuatan mendapat presentase kelayakan $86,8 \%$, pada aspek 4 tentang penggunaan mendapat presentase kelayakan $92 \%$. Jumlah skor penilaian 76 dari 18 indikator penilaian. Rata-rata penilaian validator ahli media yaitu 4,23 dengan presentase kelayakan sebesar $84,7 \%$. 
Tabel 3. Hasil Penilaian Validasi Pendidik

\begin{tabular}{|c|c|c|c|c|c|c|c|c|}
\hline \multirow{2}{*}{ No } & \multirow[t]{2}{*}{ Aspek } & \multicolumn{5}{|c|}{ Persentase kelayakan } & \multirow{2}{*}{$\begin{array}{l}\text { Rata-rata } \\
\text { persentase }\end{array}$} & \multirow{2}{*}{$\begin{array}{c}\text { Tingkat } \\
\text { kelayakan }\end{array}$} \\
\hline & & IN & EY & IR & RG & WY & & \\
\hline 1 & Materi & 86 & 86,8 & 90 & 90 & 76,6 & 85,88 & $\begin{array}{l}\text { Sangat } \\
\text { layak }\end{array}$ \\
\hline 2 & Penyajian & 91,4 & 85,6 & 82,8 & 91,4 & 85,6 & 87,36 & $\begin{array}{l}\text { Sangat } \\
\text { layak }\end{array}$ \\
\hline & $\begin{array}{l}\text { ata-rata } \\
\text { rsentase }\end{array}$ & 88,7 & 86,2 & 86,4 & 90,7 & 81,1 & $86,62 \%$ & $\begin{array}{l}\text { Sangat } \\
\text { layak }\end{array}$ \\
\hline
\end{tabular}

Berdasarkan penilaian dari validator oleh Guru TK dapat dilihat memiliki tingkat kelayakan yaitu sangat layak dengan persentase kelayakan 86,62\%. Adapun rincian validasi oleh ibu Indiarti,S.Pd memperoleh rata-rata persentase 88,7\% dengan kategori penilaian "Sangat Layak", untuk hasil validasi ibu Erma Yenti, S.Pd memperoleh rata-rata persentase $86,4 \%$ dengan kategori penilaian "Sangat Layak". Selanjutnya hasil rata-rata persentase oleh ibu Iyatmi Roza, S.Pd sebesar 86,2\% dengan kategori penilaian "sangat layak", untuk validasi oleh ibu Ria Gustina, S.Pd terhadap produk yang dikembangkan memperoleh kategori penilaian "Sangat Layak" dengan rata-rata persentase 90,7\% dan validasi oleh ibu Wisri Yeni, S.Pd memperoleh rata-rata persentase $88,7 \%$ dengan kategori penilaian "Sangat Layak"

Pembahasan dari hasil penelitian ini mengembangkan sebuah media getar (geometri putar). Pembuatan sebuah media tidak hanya sekedar membuat tetapi harus memiliki tujuan, media dikatakan baik ketika mampu memerikan respon dan antusias pada dalam proses pemebelajaran (Putri Anggraini,2019). Kevalidan media pembelajaran ditentukan dengan menghitung rata-rata nilai aspek untuk tiap-tiap validator (Febi Ancitika Pratiwi,2020). Hasil penilaian ahli materi yang dilakukan oleh validator ahli materi dari prodi PG PAUD Universitas Riau yaitu bapak Dr.Daviq Chairilsyah, S.Psi, M.Psi melakukan penilaian terkait dengan aspek materi. Kegiatan validasi pada validator ahli materi hanya melalui 1 tahap. Ada 2 aspek yang dinilai yakni Materi dan Penggunaan. Hasil penilaian mendapatkan nilai rata-rata 4,57 dengan kriteria persentase kelayakan $90 \%$ dengan kategori penilaian adalah "sangat layak".

Hal ini sejalan dengan penelitian (Viska Mei Arini, 2017) yang menyimpulkan bahwa permainan bangun geometri untuk meningkatkan kecerdasan visual-spasial anak kelompok A menurut ahli materi masuk dalam kategori sangat valid dengan persentase 97,2\%. Sejalan dengan penelitian Lailatul Asmaul Chusna (2019) yang menyimpulkan hasil validasi ahli materi pada permainan dakon geometri mendapatkan persentase 100\% dengan kategori sangat layak untuk meningkatkan kemampuan geometri anak usia 4-5 tahun.

Hasil penilaian ahli media pada validasi yang dilakukan oleh validator ahli media dari prodi PG PAUD Universitas Riau yaitu bapak Drs.Zulkifli,N, M.Pd melakukan penilaian dan memberikan saran terkait aspek media. Kegiatan validasi pada validator ahli media hanya melalui 1 tahap. Ada 4 aspek yang dinilai yakni segi Fisik, segi estetika, teknik pembuatan, dan penggunaan. Hasil penilaian mendapatkan nilai rata-rata 4,23 dengan kriteria persentase kelayakan 84,7\% dengan kategori penilaian "Sangat Layak". Putri Anggraini (2019) dalam penelitiannya menyatakan hasil validasi oleh validator ahli media mendapatkan persentase sebesar $85 \%$, maka dapat disimpulkan bahwa permainan roda putar layak untuk meningkatkan kemampuan geometri anak usia 4-5 tahun.

Sejalan dengan penelitian (Yulinda Paripurnanti, 2016) dimana hasil penilaian dari ahli media dalam pengembangan permainan colour stick geometri mendapat persentase sebesar 83,3 dengan kategori sangat layak untuk digunakan sesuai revisi dari ahli media. Sehingga Media Getar (geometri putar) yang dikembangkan sudah layak untuk digunakan dan perlu dilakukan revisi sesuai saran dari validator ahli media. Adapun revisi yang dilakukan terhadap produk Media Getar (geometri putar) adalah sebagai berikut:

1) Kombinasi warna biru dan hijau kurang menarik.

2) Kembangkan lagi media yang lebih menarik dari segi keserasian dan bentuk warna yang lebih ceria, tulisan yang lebih besar dan berwarna-warni. 
Pada saat melakukan perbaikan yang telah disarankan oleh ahli media, peneliti mengacu pada fungsi media menurut Badru Zaman (2015) yang berpendapat bahwa syarat media salah satunya harus memperhatikan syarat estetika. Unsur ini sangat penting diperhatikan karena akan memotivasi anak dan menarik perhatian anak untuk menggunakannya, syarat estetika ini menyangkut warna (kombinasi warna) serasi dan menarik. Warna dalam mendesain suatu produk merupakan unsur yang sangat penting karena akan memberikan dampak psikologis bagi yang melihatnya (Azhar Arsyad. 2013). Maka dari itu, peneliti mengubah warna biru pada produk dengan warna merah muda, sehingga warna yang tadinya kurang menarik, menjadi warna yang lebih menarik bagi anak.

Selain itu, pada bagian tulisan pada bentuk-bentuk geometri peneliti mengacu pada pendapat C.Asri Budiningsih (2012) yang mengatakan bahwa pemilihan jenis dan ukuran huruf disesuaikan dengan karakteristik anak agar lebih menarik, bentuk huruf yang dipilih harus kontras antara huruf dengan latar belakangnya agar pesan pembelajaran yang terdapat dalam tulisan dapat terbaca dengan baik oleh anak. Maka peneliti mengubah ukuran tulisan bentukbentuk geomteri yang awalnya kecil dirubah menjadi lebih besar dan berwarna yang kontras dengan Media Getar (geometri putar).

Respon pendidik bernilai positif jika persentase respon memperoleh $>80 \%$ dari aspek yang di teliti, sedangkan untuk makna repon negatif bermakna sebaliknya Hobri (dalam Friska Apriyani, 2018). penilaian dari ke 5 guru sertifikasi mendapat persentase sebesar 86,62\% dengan kategori "sangat layak" Sehingga Media Getar (geometri putar) yang dikembangkan sudah layak untuk digunakan. Sejalan dengan penelitian Mawaddah Warohmah (2019) menyimpulkan media pembelajaran menggunakan permainan Gotri Legendri mampu meningkatkan kemampuan geometri anak usia 4-5 tahun dengan indikator keberhasilan sebesar $85 \%$.

\section{SIMPULAN}

Media Getar (geometri putar) layak digunakan sebagai media pembelajaran untuk mengingkatkan kemampuan mengenal bentuk geometri anak usia 4-5 tahun bedasarkan penilaian validator ahli media, ahli materi dan 5 guru TK sertifikasi.

Sesuai dengan kesimpulan hasil penelitian, maka dapat dikemukakan beberapa rekomendasi yaitu:

1. Bagi peneliti selanjutnya, diharapkan dapat mengembangkan sebuah media pembelajaran yang baru untuk meningkatkan kemampuan mengenal bentuk geometri yang belum ada pada Media Getar (geometri putar). Sehingga media yang digunakan untuk kegiatan bermain sambil belajar di TK lebih bervariasi dan dapat meningkatkan efektivitas pembelajaran. Karena semakin menarik suatu media pembelajaran kedepannya akan memberikan dampak yang positif bagi perkembangan anak dalam proses pembelajaran karena anak tidak merasa bosan dengan media pembelajaran yang monoton.

2. Bagi pembaca dapat melakukan pengembangan lebih lanjut terhadap media pembelajaran terutama Media Getar (geometri putar) agar dapat dihasilkan produk yang inovatif untuk digunakan dalam pembelajaran, media ini dapat diujikan kepada kelompok yang lebih luas, bukan hanya sampai tahap validasi saja tetapi diuji cobakan ke sekolah atau lembaga pendidikan yang terkait untuk melihat seberapa besar pengaruh media dalam meningkatkan kemampuan geometri anak usia dini.

3. Bagi guru dapat memanfaatkan atau menggunakan Media Getar (geometri putar) dalam proses pembelajaran sehingga kemampuan mengenal bentuk geometri anak berkembang secara optimal.

\section{DAFTAR PUSTAKA}

Agung Triharsono. 2013. Permainan Kreatif dan Edukatif untuk Anak Usia Dini. C.V Andi Offset. Yogyakarta.

Azhar Arsyad. 2013. Media Pembelajaran. Raja Grafindo Persada. Jakarta.

Badru Zaman. 2015. Media dan Sumber Pembelajaran TK. Universitas Terbuka. Jakarta.

C. Asri Budiningsih. 2012. Belajar dan Pembelajaran. Rinekacipta. Jakarta 
Febi Acitika Pratiwi. 2020. Pengembangan media pembelajaran puzzle menggunakan teka-teki silang pada materi sistem peredaran darah manusia kelas vii smpn 1 tembilahan. Jurnal FKIP.

Friska Apriyani. 2018. "Pengembangan Media Dadu Dan Papan Flannel Untuk Meningkatkan Kemampuan Mengenal Konsep Geometri Pada Anak Kelompok A RA Perwanida 1 Cluring". Skripsi. Universitas Jember.

Hesti Nurhayati. 2015. "Pengembangan Alat Permainan Edukatif Rumah Kata Untuk Anak TK Kelompok B". Skripsi. Universitas Negeri Yogyakarta. Yogyakarta.

Lailatul Asmaul dan Mallevi Agustin. 2019. "Pengembangan Media Dakon Geometri Untuk Meningkatkan Kemampuan Mengenal Bentuk Geometri Anak Usia 4-5 Tahun”. Jural FKIP Universitas Negeri Surabaya.

Latif, Zukhairina,dkk. 2013. Orientasi Baru Pendidikan Anak Usia Dini (Teori dan Aplikasinya). Gelora Aksara Pratama. Jakarta.

Mawadah Warohmah. 2019. "Meningkatkan Kemampuan Mengenal Bentuk Geometri Melalui Permainan Tradisional Gotri Legendry Kelompok A di RA Albidayah Candi Bandungan". Skripsi. IAIN Salatiga.

Putri Anggraini. 2019. "Pengembangan Media Roda Putar Untuk Meningkatkan Kemampuan Mengenal Betuk Geometri Anak Usia 4-5 Tahun". Jurnal FKIP. Universitas Negeri Surabaya.

Riduwan. 2012. Pengantar Statistik Sosial. Alfabeta. Bandung.

Sugiyono. 2013. Metode Penelitian Pendidikan Kuantitatif dan Kualitatif dan $R$ \& D. Alfabeta. Bandung.

Viska Mei Ariani. 2017.Pengembangan Permainan Bangun Geometri pada Pembelajaran Visual-Spasial untuk Anak Kelompok A TK Kartika IV-8 Kabupaten Jember. Jurnal FKIP. Universitas Negeri Malang.

Wahyudi CHA dan Dwi Retno Damayanti. 2005. Program Pendidikan untuk Anak Usia Dini di Pra Sekolah Islam. PT Gramedia Widiasarana Indonesia. Jakarta.

Yulinda Paripurnanti. 2016. Pengembangan Permainan Colour Stick Geometri dalam Pembelajaran Kognitif Anak TK Kelompok B.Jurnal FKIP. Universitas Negeri Malang. 